\title{
Research on Status Quo of Body-building Projects for Farmers in Hubei Province and Its Countermeasures
}

\author{
Hao Xiong \\ Hubei Business College \\ Wuhan, Hubei, China 430079
}

\begin{abstract}
As an agricultural country developing at a high speed, China has sports activities carried out in most of the rural areas, which play an important role in strengthening physical bodies of farmers, enriching amateur and cultural life as well as building harmonious and new villages across the country. This article conducts researches on the status quo, relevant factors, development modes and countermeasures relative to the bodybuilding project of farmers in Hubei Province. The research results show that many problems are found such as lack of local rules for body-building of farmers, confused management system and operating mechanism; inadequate supporting funds in some areas; serious lagging of national service coordination system construction for the diversified body building of farmers; overall quality of professional instructors and managements urgent for improvement for the body-building of farmers. Based on analysis, this article proposes relevant measures for optimization and development: promulgate and improve local laws and regulations relative to "Body-building project of farmers", and list the construction of "Body-building project of farmers" to the overall development layout of the rural construction, which is a basic guarantee for carrying out the "Body-building project of farmers"; the "Body-building project of farmers" shall go together with education, culture, health, medical care and more to form a diversified national service coordination system in order to promote the "Body-building project of farmers" and make it work well in practice.
\end{abstract}

Keywords-Hubei Province; body-building project of farmers; survey; analysis

\section{INTRODUCTION}

New village construction is a major strategic measure of building a harmonious and well-off society in all aspects in the new century. The wide development of sports undertakings and sports activities in rural areas can not only improve the health quality of farmers, better the quality of life, but also boom the advanced culture, guide the farmers to upgrade outdated customs, enhance the civilization of the rural areas and farmers, and form harmonious interpersonal relationship and promote the construction of new socialist villages. Over than 30 years after China's opening up, the production level in rural areas, Hubei Province, has got improved rapidly and the economic development speed is faster than ever. However, what going against the booming economy in rural areas, Hubei Province is the poor development of body -building project of farmers, who have lower consciousness in body building. Therefore, under the grand background where we are building a socialist harmonious society, it has an important practical significance on how to make villages actively meet the needs of a harmonious society, create and optimize a body-building project of farmers which support the new village construction, serve most farmers, have rural characteristics and satisfy different people in the need of body building. Besides, the research can be used as reference or inspiration for this province to explore a body-building system for farmers, featuring scientific, reasonable and efficient.

In view of this point, this research is to introduce a concept of project management, trying to make use of limited funds and resources, with as low as costs, as fast as it can as well as excellent quality to complete the project, so as to make it done as expected with social benefits obtained as scheduled.

\section{STATUS QUO AND ANALYSIS}

\section{A. Fund Source}

There are four sources of funds for the body-building project of farmers in Hubei Province, namely: first, special investments of the sports authorities at all levels; second, annual investment by Hubei Agricultural Department; third, sports lottery business; fourth, sponsorship by enterprises, institutions or individuals. However, as a whole, there are no adequate funds for the body building projects of farmers, and the investment mode is relatively single. The few sources for funds and low investment have become a main factor to restrict the development of the body- building projects of farmers in Hubei Province.

\section{B. Management and Operation Mechanism}

Starting from 1987, farmer sports associations were established successively in 21 prefecture-level cities, 23 county-level cities, 41 counties, 3 autonomous counties, 1145 towns, 4 townships, 7 ethnic townships in Hubei Province, which have become vital forces for the development of sports undertaking in rural areas across the country. The body building projects of farmers shall be mainly based on the construction of the public sports places at the village level, and it needs to create a long-term mechanism for the harmonious development in the sport places, sports organization, backbone teams and sports activities, for it is initially started, there are no proved models experience for reference. Due to the lack of supporting management by farmer sports associations of social nature, the administrative framework for management of body 
building projects of farmers belongs to typical vertical administrative structure. Obviously, the management mode of current body building projects of farmer falls behind the requirements of the socialized mass sports management model, which is unsuitable for the body building projects of farmers and or the sustainable development. The improper institution setting is a main reason leading to the poor management of farmers' sports in towns, which is reflected by few communications between the farmer's sports associations in towns and the above-level sports authorities, unclear in rights and responsibilities; ration imbalance of genders for persons in charge of the sports management as well as lower educational background. Imperfect systems for the body building projects of farmers. Another important reason is that there is no a perfect place and equipment management system applicable for villages where the body building projects of farmers are launched, which is a barrier for the healthy development of the body building projects. In addition, due to the short term for the completion of body building projects of farmers, currently there are few sport organizations which are established by the body building projects of farmers. Though authorities have strengthened the management on sports and organization in villages, yet it still needs to be further accelerated, especially in the construction of sports organizations in remote areas.

\section{Training of Instructors for Social Sports}

According to surveys, by the end of Dec 2016, there had been 112,980 instructors for social sports in Hubei Province, averagely 10 for ten thousand people, going ahead of the country. At present, of the instructors for social sports in villages, Hubei Province, 660 persons get Level I certificate and 1,550 persons get Level II certificates. After training and evaluation, the business capabilities of sports backbones in villages in the province have been greatly improved as well as with updated concepts and broadened views. A basic network framework has come into being where there are sports associations in counties(cities and districts), cultural and sports stations in towns, instructors for social sports and sports backbones in most villages as well as a four-level body building organizations at province, city, county and village levels. The increasingly perfect body building organizations and the growing instructor teams for social sports have played an important role in guiding the scientific body building of the people in this province. However, the training of instructors for social sports in villages is initially started, and the proportion of instructors owning certificates of instructors for social sports is still lower. Seen from the ratio between the numbers of farmers and that of instructors for social sports in Hubei Province, whether in the number or quality, the instructors for social sports in villages are far to meet the needs of healthy development of sports in villages.

\section{Sport Field Construction and Management}

The implementation plan of the body-building projects of farmers requires that the standard for the construction of the body-building projects of farmers in Hubei Province shall be a standard concrete basketball court, equipped with standard basketball stands and two outdoor table tennis tables. The standard concrete basketball court shall be designed and built in accordance with the Design Code for Sports Buildings of the
Ministry of Construction and the General Administration of Sport. Open up smooth empty lands of $5 \mathrm{~m}$ at least around the basketball court $(28 \mathrm{~m} \times 15 \mathrm{~m})$ so as to make it easy for audiences to watch sport games or carry out other workouts. The land occupation of single table tennis place shall be not less than $7 \mathrm{~m} \times 5 \mathrm{~m}$, based on which, it is suggested that the areas with developed economy and large population should expand the land occupation, increase equipment and facilities with the agreements of farmers around so as to build a cultural sports square and meet the needs of culture and sports in villages. Though the construction of body-building projects of farmers is in a high speed, the hardware facilities are far to meet the needs of the people for sports development.

In addition, the routine maintenance and repair of equipment and facilities for the body-building projects of farmers are mainly undertaken by the village committees, $36.4 \%$ of administrative villages pay 50-300 yuan per month from the village finance and hire part-time workers in charge of the site facilities management and maintenance; $18.9 \%$ of the administrative villages have no workers for management, the rest of the administrative village are concurrently managed. All cadres from sampled villages all agree to assume the maintenance and management of the places and equipment. There are no any administrative villages which establish special rules to protect and manage the places and facilities for the body-building projects of farmers, of whom, a few carders agree to borrow the public management rules of the villages, and most of the cadres agree to establish specific management rules going with the development of the body-building projects of farmers.

\section{E. Service Conditions}

The survey on the body building projects of farmers in Hubei Province turns out that there are three types that farmers participate in the sports activities namely individual, play together with villagers, participating in activities organized by others. It proves that the body building projects of farmers in Hubei Province are poorly organized, non-governmental sports organization are restricted by impersonal material conditions, costs, organization and management level and so on, as a result, it fails to fully drive the public sports activities.

The residents in some villages where the body-building projects pilot of farmers are launched still hold their thoughts on basketball courts, table tennis tables and the like, and there are efficient measures to make use of the body-building projects to improve villagers' quality and to improve the images of villages.

A survey made on methods of farmers' participation in sports activities in Hubei Province shows that the number of farmers who select basketball projects for sport activities ranks the first, accounting for $35.9 \%$ of the total number surveyed; Followed by the farmers who select table tennis as their preferred project, accounting for $20.4 \%$ of the total number surveyed; In addition, the number who select walking and gymnastics account for $12.6 \%$ and $13.6 \%$, respectively and only $11.8 \%$ of farmer select labors as their preferred way for sports activities. After analysis, this author thinks that the farmers in Hubei Province are accustomed to selecting the 
existing sports facilities for body building, which do good to the continuous and healthy development of the body - building projects of framers in the province.

According to the survey made on purposes of farmers' participation in the body-building projects in Hubei Province, we can find that the farmers who hope to improve the health, build the bodies and promote the interpersonal communication occupy $90 \%$ or more of the surveyed, which turns out that most of the farmers in Hubei Province have been aware of the value of sports activities and established correct values of exercise.

The survey results on the factors which influence the effect of body-building projects of farmers show: First, farmers have lower consciousness of sports, the consciousness of sports is an internal factor which promote farmers to participate in the body-building projects of farmers, if having no such consciousness, even the body building projects of farmers are well built, it cannot work, failing to do as required and reach the final purpose; Second, the stressing and support of leadership play a key role in the implementation and development of the body building projects of farmers; Third, main difficulty to carry out the body-building projects of farmers is the lack of places and facilities. The complete facilities are the basis for sports activities of farmers, ye the lack of places and facilities are caused by the inadequate costs, all of the problems directly influence the construction the body-building projects of farmers as well as the implementation of the sports activities; Fourth, though the sports activities are mainly organized by individuals or spontaneous, yet it still need to be kept organized and scientific; Fifth, whether the policies and rules are perfect is also a factor restricting the implementation of body-building projects of farmers. Finally, reasons of farmers themselves are also an important factor influencing the effect of the implementation of body-building projects of farmers.

\section{CONCLUSION}

Most of farmers hold consciousness at a lower level to participate in sports activities, therefore, the sports authorities at all levels should actively create atmospheres for sports activities and strengthen the consciousness of farmers for body building.

White improving the hardware facilities for the bodybuilding projects of farmers, is shall cope with education, culture, health, medical care and health care to create a diversified national service coordination system in order to promote the "Body-building project of farmers" and make it work well in practice.

Authorities at all levels should fully mobilize relevant departments such as finance, education, sports, agriculture, publicity and so on to increase investments to the body building projects of farmers, establish more agencies for training of sports talents in villages, formulate laws and regulations and the operation mechanisms of the body-building projects, strengthen the propaganda. This government-led model may well drive the rapid and healthy development of the body-building projects of farmers.
Make full use of traditional Chinese holidays to carry out sports activities in villages, organize sports activities with local characteristics and features of the time, and combine the sports activities with productive labors and cultural life.

\section{REFERENCES}

[1] Zhang Chuanyi, Ren Baoguo, Research on Social Value of Efficient Construction of Body-Building Projects for Farmers in New Villages [J] Sports \& Science, 2010,31(3):56-60

[2] Jiang Liang, Rao Ping, Mo Yingrui, Sociological Perspective of Sports Development in Villages during the Construction of New Villages [J]. Journal of Beijing Sport University, 2008.(11).

[3] Peng Jianjun, Zhong Qin, et al, Research on the Body Building Projects of Farmers and Implementation Effect in Hubei Province $[\mathrm{J}]$ Journal of Wuhan Institute of Physical Education, 2011(10)

[4] Zhang Guanglin, Discussion on the Construction of Sports Activities Information Service System for Weak Groups in Towns [J] Gansu Science \& Technology, 2007(5).

[5] Tai Chongxi, et al, Construction of Body-Building Projects of Farmers around Taihu Lake [J] Journal of Physical Education, 2008(12)

[6] Da Houlin, Shi Qingfu, Thought about Carrying out the Body-Building Projects of Farmers [J] Sports World, 2009(9)

[7] Zheng He, Thought about Relations between Building Well-off Society and Public Sports Activities [J]. Journal of Shanghai University of Sport, 2005(2).

[8] Lu Wenyun, Historical Views on Farmers' Sports Practices since China's Foundation [J] Journal of Physical Education, 2006(1). 